\title{
The Forms of Nitrogen in the Coal Char and Analysis of Char-nitrogen Conversion by TG-FTIR
}

\author{
Jing Xin*, Baomin Sun, ShuJian Yin, Hengyi Zhu, Qiang Liu, Xiao Luo, Haiping Xiao \\ MOE's Key Lab of Condition Monitoring and Control for Power Plant Equipment \\ North China Electric Power University, Beijing102206, China \\ E-mail: *whxinjing@sina.com
}

\begin{abstract}
The forms of nitrogen in experimental blended coal/char and combustion characteristics as well as char-nitrogen conversion rules of the char in air atmosphere were investigated by the ways of X-ray photoelectron spectroscopy (XPS) and thermogravimetry-fourier transform infrared spectroscopy (TG-FTIR). The results show that the pyrrolic nitrogen (N-5) in char is relative instability after high-temperature pyrolysis by comparing main occurrence modes of nitrogen between the experimental blended coal and the corresponding char. The TG curve of experimental char gradually falls in the range of $460 \sim 756{ }^{\circ} \mathrm{C}$ and the DTG curve reaches the peak at $666{ }^{\circ} \mathrm{C}$. The activation energy of the char combustion is $93.9 \mathrm{KJ} / \mathrm{mol}$ in the range of the same temperature above based on the method of Coats-Red fern. The main gases include $\mathrm{CO}_{2}, \mathrm{CO}, \mathrm{NO}, \mathrm{NO}_{2}, \mathrm{~N}_{2} \mathrm{O}, \mathrm{HNCO}$ and $\mathrm{HCN}$.
\end{abstract}

Keywords: Blended coal; coking; char-nitrogen; TG-FTIR; thermodynamics.

\section{Introduction}

Coal is the most important resource in Chinese energy consumption structure. $70 \%$ of coal is used for power generation. The main process of coal combustion includes the formation of char with the release of volatile gas and the combustion of char [1]. The combustion of char is a physical and chemical reaction affected by many factors. It accounts for over $85 \%$ of the whole process of pulverized coal combustion. During the process of high-temperature reaction, volatile gas is released in steps, and different forms of char are produced in each step. The physical and chemical characteristics of char have a direct effect on the coal conversion [2].

In recent years, the blended coal combustion phenomena have been popular in China in order to relieve the tension of coal supply. The practical operating experiences show that there are many differences in combustion characteristics of blended coal, comparing with the single coal [3]. The blended coal combustion also leads to some environment pollution problems. In recent years, more and more strict Chinese emission criterions of nitrogen oxides $\left(\mathrm{NO}_{x}\right)$ have made the study of single coal and nitrogen functional groups a heat. Studies indicate charnitrogen can be divided into two types: volatile-nitrogen (Vol-N) and char-nitrogen [4]. The forms of nitrogen in the blended coal/char have great effect on the structure of coal molecule as well as processing and transforming of coal. But the relative literatures are limited. Diffident forms of nitrogen in the blended coal/char determine the differences in the blended coal/char reaction. Consequently the studies of char-nitrogen conversion rules during the char combustion process and the forms of nitrogen in the blended coal/char are important to high efficient and clean utilization of blended coal/char. The studies indicate X-ray photoelectron spectroscopy (XPS) is an effective way to analyze surface chemical elements. It has been widely used in recent years. XPS has minimize damages to the surface of samples and provides qualitative and quantitative study of all the chemical elements on the surface of the samples (expect $\mathrm{H}$ and $\mathrm{He}$ ) [5]. As a result, it is very meaningful to study forms of nitrogen in blended coal/char and charnitrogen conversion rules of the char by the ways of XPS.

With the increase of the coal metamorphic grade, the maximum weight loss rate of samples declines sharply and the maximum weight loss temperature ascends rapidly in thermogravimetric (TG) curve. The phenomenon indicates that the tighter bonds of the molecules, the more energy they require to break molecular bonds during the combustion and pyrolysis process [6]. The thermogravimetric analysis by itself does not identify the decomposition products. When TG analysis is coupled with other methods, more information can be obtained. Fourier transform infrared spectroscopy (FTIR) is a common realtime analysis method of gases. By the analysis of nonisothermal combustion gases, the characteristics of char combustion can be acquired qualitatively. Thermogravimetry-Fourier transform infrared spectroscopy (TG-FTIR) has great accuracy and sensitivity as well as reproducibility. And it can be used for real-time analysis to collect instant information of gaseous productions [7].

There are quite a few literatures about the study of single coal/char combustion behavior and char-nitrogen conversion rules of nitrogenous compounds using TGFTIR. Nitrogen heterocyclic rings are exposed to the outermost layer with the heat of the char and char-nitrogen is released with the break of the rings. HCN was proved to be an important nitric gas-production of the char in low temperature combustion by Ashman et al.[8]. A test for the gases released in the oxygen-enriched combustion of single char was done by Chen et al.[9] with TG-FTIR. The results show the trend of the formation of $\mathrm{HCN}, \mathrm{HNCO}$ and $\mathrm{N}_{2} \mathrm{O}$ is fundamentally the same. But the studies of the combustion characteristics of the chars blended by multiple coals

are

rarer 
The forms of nitrogen in experimental blended coal/char and combustion characteristics as well as char-nitrogen conversion rules of the char in air atmosphere were investigated by the ways of X-ray photoelectron spectroscopy (XPS) and TG-FTIR in this article. This article can provide a reference and basis for mastering the forms of nitrogen in the blended coal/char and combustion characteristics as well as char-nitrogen conversion rules of the blended coal char.

\section{Experimental Samples and Methods \\ 2.1 Preparations of the Blended Char}

The raw experimental coal samples (blended coal $\boldsymbol{A}$ ) was a blend of $84 w t \%$ blended bituminous coal and a blend of $16 w t \%$ blended anthracite. Among them, the blended bituminous coal was a blend of three bituminous coals in a 1:1:1 ratio. The blended anthracite was also a blend by three anthracites in the same ratio. All the above single coals ware obtained from a certain power station. The single coals were sieved and then the coal under the 200mesh $(75 \mu \mathrm{m})$ sieve was divided according to GB74-1996 (in China) of the standard coal preparation method. The coals were dried and divided by the method of coning and quartering to prepare the samples on air dried basis after well mechanical and artificial mixing according to the above mass proportion. The samples were then put into wide-mouth bottle with serial numbers. The characteristic parameters of the blended coal are showed in Table 1.

Table 1. Proximate and Ultimate Analysis of the Blended Coal.

\begin{tabular}{lcl}
\hline Coal & Blended coal $A$ & Value \\
\hline \multirow{2}{*}{ Chemical analysis(\%) } & $\mathrm{C}_{\mathrm{ar}}$ & 56.65 \\
& $\mathrm{H}_{\mathrm{ar}}$ & 3.27 \\
& $\mathrm{~S}_{\mathrm{ar}}$ & 2.82 \\
& $\mathrm{~N}_{\mathrm{ar}}$ & 0.89 \\
& $\mathrm{O}_{\mathrm{ar}}$ & 3.90 \\
\hline & $\mathrm{M}_{\mathrm{ar}}$ & 4.73 \\
& $\mathrm{~A}_{\mathrm{ar}}$ & 27.74 \\
& $\mathrm{~V}_{\mathrm{ar}}$ & 22.62 \\
\hline
\end{tabular}

The formation method of the char corresponding to the blended coal $\boldsymbol{A}$ was as follows. The crucible (dry and clean) full with the blended coal was put in the muffle furnace and heated up to $950{ }^{\circ} \mathrm{C}$ for 30 minutes in order to release the volatile completely. During the heat process, the crucible was plugged to keep the coal away from the air, so the relevant reactions could not occur. The char produced by the blended coal was cooled naturally before it was put into the drying vessel to be cooled down to room temperature. After the cooling, the char was tightly sealed and kept. The char sample produced by the blended coal $\boldsymbol{A}$ was called char $\boldsymbol{a}$.

\subsection{Spectrogram of XPS}

$\mathrm{X}$-ray photoelectron spectroscopy (XPS) is ThermoVG ESCALAB 250. It consists of monochrome X-ray source, double anode $(\mathrm{Al} / \mathrm{Mg})$ X-ray source, oil-free vacuum system, ion etching, XPS imaging system, neutralizer gun, ion gun of $\mathrm{Ar}$ and so on. All elements from Li to $\mathrm{U}$ can be analysed with the sensitivity of $0.1 \%$ to $1 \%$ in atom concentration ratio. The test scanning step was $0.05 \mathrm{eV}$ and C1s (284.6 eV) was adopted as standard in this paper. All samples were tested in the same condition.

\subsection{The Equipment and Method of Thermogravimetric Experiment}

The thermogravimetric experiment was performed in a SDT (Q600) simultaneous thermal analyzer. The main analyzer components include a balance recorder, a heating furnace, a temperature procedure controlling system, a recorder, and a holder. The operating temperature ranged from room temperature to $1500{ }^{\circ} \mathrm{C}$ with heat-up rate of $1 \sim 100{ }^{\circ} \mathrm{C} / \mathrm{min}$ and cooling rate of $50{ }^{\circ} \mathrm{C} / \mathrm{min}$ (in the range above $50{ }^{\circ} \mathrm{C}$ ). The accuracy of thermometry was $\pm 0.5 \%$ and the reproducibility of temperature was less than \pm $0.5 \%$. The balance was vertical with single beam and its sensitivity was $0.1 \mu \mathrm{g}$. The accuracy and the sensitivity of the calorimeter were $\pm 2 \%$ (based on a melting standard of metal). The maximum mass of loading samples was less than $200 \mathrm{mg}$.

The experiment used char a of $10 \pm 1 \mathrm{mg}$ with the heat rate of $20^{\circ} \mathrm{C} / \mathrm{min}$ in the range of $22{ }^{\circ} \mathrm{C} \sim 1000{ }^{\circ} \mathrm{C}$. Air was used to be the carrier gas and its flow rate was $60 \mathrm{~mL} / \mathrm{min}$ considering the mixing of the spilled gas and the sensitivity of infrared detection. The char was heated from room temperature to about $1000{ }^{\circ} \mathrm{C}$ in order to ensure a thorough burning. The heat was stopped after the thermal analysis curve was stable.

\subsection{Infrared Spectrometric Analyzer}

Infrared spectrometric analyzer (manufactured by PE of USA) is composed by a light source, a Michelson interferometer, a sample pool, a detector and a computer. The single-beam infrared spectroscopy method was used and the range of light path was from $0.5 \mathrm{~m}$ to $12.5 \mathrm{~m}$. The volume of the sample pool was $2.23 \mathrm{~L}$ in this paper. As shown in Figure 1, the infrared gas pool is composed with a bronze cylinder in the middle and resin glass at both ends. These components make it a carrier with both ends pervious to light and a middle part blacking out. The gas is exhausted from the vents and enters into the gas entrance along the airway tube for infrared analysis before being exhausted from the gas vent. This design makes the pipes of gas pool shorter and reduces time of air conduction. And the gas produced by the char is blown away in time so it can be assumed the secondary reaction doesn't happen and thus the analysis factors are simplified.

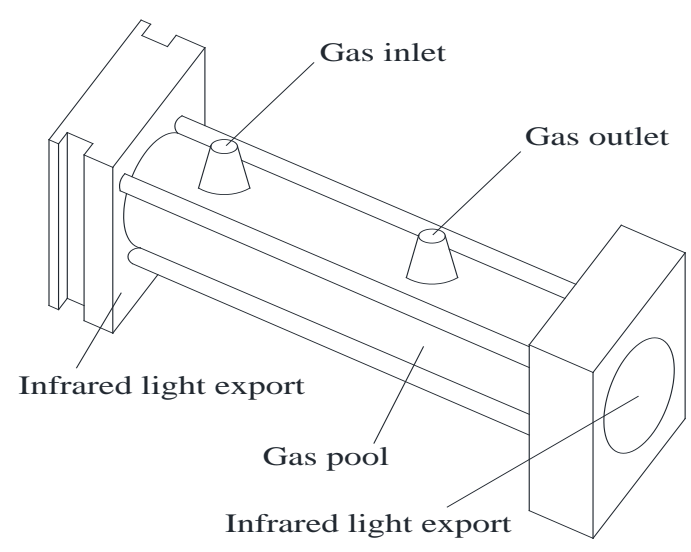

Figure 1. Schematic of the gas pool in FTIR. 


\section{Results and Analysis}

\subsection{The Main Forms of Nitrogen}

\subsubsection{The Experiment for Nitrogen Forms in the Blended Coal/Char}

The spectra were smoothed and Shirley background was subtracted. The calibration was carried out to the main $\mathrm{C}$ 1s peak at $284.6 \mathrm{eV}$. An analytical model of the peak shape (Gaussian multiplied by Lorentzian) with a mixing ratio of 0.5 (pure Lorentzian peak: 1; pure Gaussian peak: 0) was used. The fitting procedure was based on the FWHM of $\mathrm{N}$ 1s which was fixed to $1.8 \mathrm{eV}$ [10]. The peaks in the fitted XPS spectra were assigned to the functionalities according to the binding energies (Table 2).The XPS spectra and fitting curves are presented in Figure 2.

\begin{tabular}{|c|c|c|}
\hline The form of nitrogen & Symbol & Binding energy/eV \\
\hline Pyridine nitrogen & N-6 & $398.7 \pm 0.4$ \\
\hline Pyrrole nitrogen & $\mathrm{N}-5$ & $400.5 \pm 0.3$ \\
\hline Quaternary nitrqgen & $\mathrm{N}-\mathrm{Q}$ & $401.1 \pm 0.3$ \\
\hline Nitric oxide & $\mathrm{N}-\mathrm{X}$ & $403.5 \pm 0.5$ \\
\hline
\end{tabular}
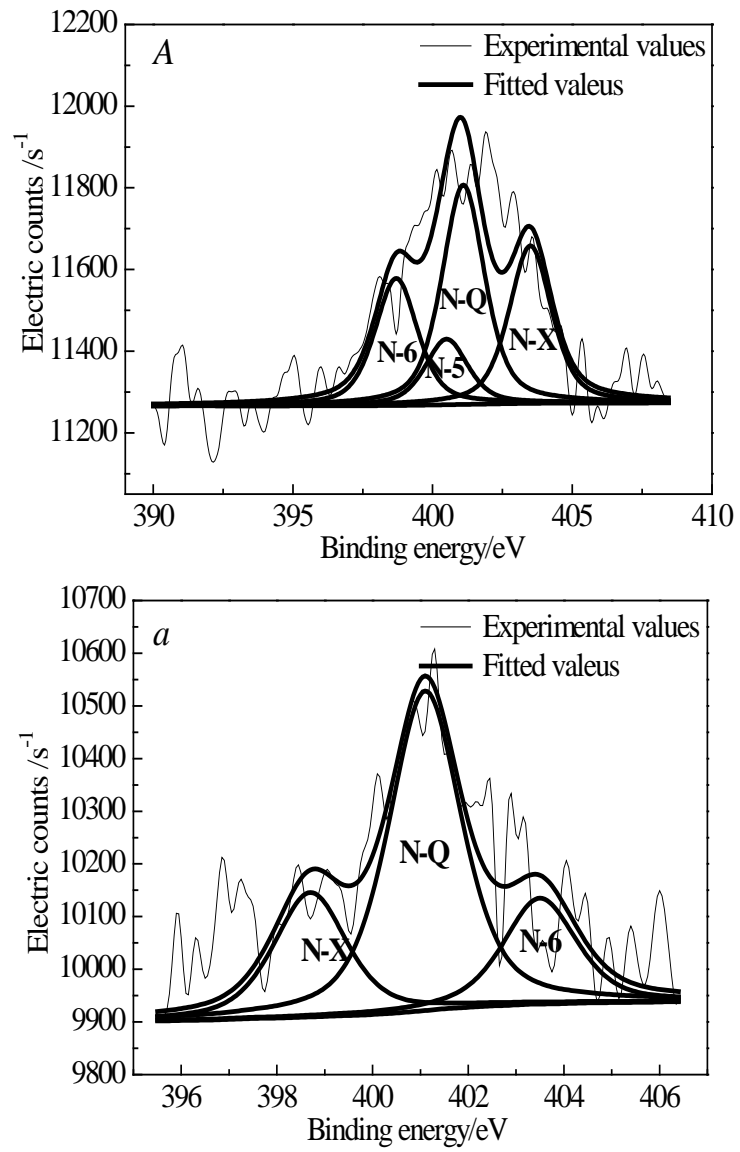

Figure 2. The XPS spectra of the blended coal $\boldsymbol{A}$ and char $\boldsymbol{a}$.

As Figure 2 shows, the nitrogen forms of blended $\boldsymbol{A}$ consist of pyrrolic nitrogen (N-5) pyridinic nitrogen $(\mathrm{N}-6)$, quaternary nitrogen $(\mathrm{N}-\mathrm{Q})$ and $\mathrm{N}-\mathrm{X}$ (chemisorbed nitrogen oxides). While the nitrogen forms in the corresponding char consist of N-6, N-Q and N-X. The nitrogen forms change in the char generation process from the blended coal and there is no N-5 in the corresponding char compared with the coal. It indicates that $\mathrm{N}-5$ is not stable during high temperature pyrolysis process. In the pyrolysis process, it is released in forms of gaseous volatiles or converted into N-6 or N-Q. This conclusion is consistent with what other literature already reported [11].

\subsubsection{The Comparison of Single Coals Nitrogen Forms}

The nitrogen functional forms in New Zealand coal were consisted of N-6, N-5, N-Q and N-X [5]. The study showed that nitrogen presented in coal in pyrrole form (N$5)$ was converted into pyridine form (N-6) when temperature over $600{ }^{\circ} \mathrm{C}$. Several foreign coals and their corresponding char were investigated by Wojtowicz et al.[12]. Their study showed that N-6 was more stable than $\mathrm{N}-5$ and N-5 would be converted into N-6.

The blended coal used in a certain power station is chose to be experimental samples in this paper. The forms and conversion rules of nitrogen in experimental blended coal/char is consistent with the rules reported by literature mentioned above. This conclusion shows that there is no big change in $\mathrm{N}-6, \mathrm{~N}-5, \mathrm{~N}-\mathrm{Q}$ and $\mathrm{N}-\mathrm{X}$ forms between the blended and single coal/char.

\subsection{Thermogravimetric Analysis \\ 3.2.1 TG-DTG Curve}

The TG-DTG curve can be depicted according to the results of the thermogravimetric analysis. The following combustion characteristics can be obtained from the curve: (1) the maximum mass loss rate $(d w / d t)_{\max }$ during the combustion of the samples, (2) the temperature $T_{\max }$ corresponding to the maximum burning rate, (3) the ignition temperature $\mathrm{Ti}$ which is obtained from the TGDTG curve, (4) burnout temperature $T_{h}$ which represents ignition properties of coal samples (the temperature corresponding to $98 w t \%$ of the whole weight loss is usually chose to represent the burnout characteristics of the coal sample). The above parameters can reflect the combustion kinetics characteristics of a sample in the heatup process.

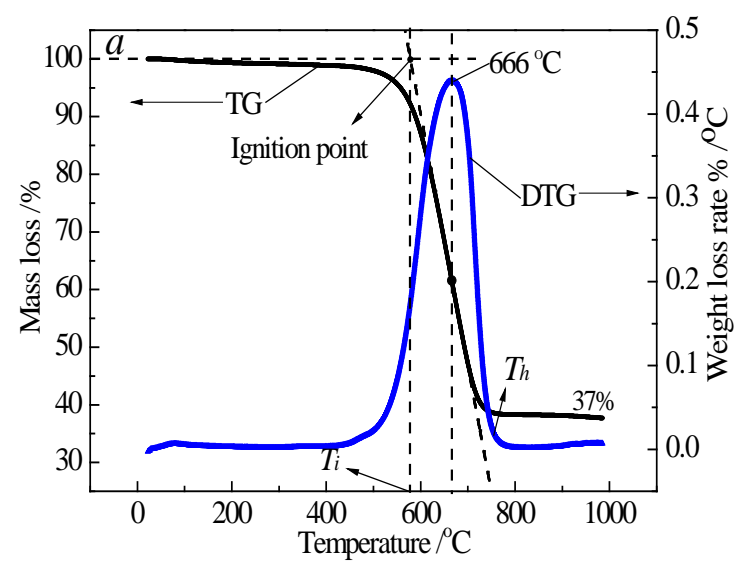

Figure 3. TG and DTG curve of the char a.

The TG-DTG curve of the char combustion in air atmosphere with weight loss ratio of $63 \%$ is depicted in Figure 3. Other combustion characteristics are as follows: $(\mathrm{d} w / \mathrm{d} t)_{\max }=0.439 \% /{ }^{\circ} \mathrm{C}, \quad T_{\max }=666{ }^{\circ} \mathrm{C}, \quad T_{i}=578{ }^{\circ} \mathrm{C}$, $T_{h}=724^{\circ} \mathrm{C}$. Figure 3 shows the combustion process of the char can be divided to three phases. In the first phase, the TG curve declines slowly from the initial temperature to $460{ }^{\circ} \mathrm{C}$ with individual peaks. The major process in this phase is the release of water and char surface adsorbed gas. The temperature of second phase is from 460 to $756{ }^{\circ} \mathrm{C}$. In this phase the TG curve declines sharply with a peak at 
$666{ }^{\circ} \mathrm{C}$. The third phase happens after $756^{\circ} \mathrm{C}$ in which the TG-DTG is more gently. The continuous reactions between unburned char and generated gas are the main process.

\subsubsection{Dynamic Characteristic of the Char}

The combustion kinetic parameters of the char are shown in Table 3 with the method of Coats-Redfern [13] (the above three phases of TG). As shown in Table 3, the activation energy in the range below $460{ }^{\circ} \mathrm{C}$ is larger. It is because the char samples are produced by high temperature pyrolysis. The molecules combined by non-covalent bonds are released during the high temperature pyrolysis process and the structures of remaining molecules are more stable. As a result, the char samples are hard to react at low temperature and require more activation energy. In the range from 460 to $756{ }^{\circ} \mathrm{C}$, the reaction is violent with the activation energy going down sharply to $93.9 \mathrm{KJ} / \mathrm{mol}$ which is consistent with the sharp drop of the TG curve at the same temperature range. In the range up to $756{ }^{\circ} \mathrm{C}$, the values of activation energy decline gradually because the reaction is facilitated by high temperature.

\begin{tabular}{llll}
\multicolumn{4}{c}{ Table 3. The Combustion Kinetic Parameters of the Char a. } \\
\hline Temperature & Activation & Pre-exponential & Correlation \\
range & energy & factor & coefficient \\
$T /{ }^{\circ} \mathrm{C}$ & $E_{a} /(\mathrm{kJ} / \mathrm{mol})$ & $A /(1 / \mathrm{s})$ & $R$ \\
\hline $22 \sim 460$ & 172.6 & 0.3 & 0.897 \\
$460 \sim 756$ & 93.9 & 70454.6 & 0.985 \\
$756 \sim 986$ & 32.2 & 14.4 & 0.921 \\
\hline
\end{tabular}

\subsection{The Analysis of Infrared Results}

According to the analysis of FTIR results (see Figure 4 and Figure 5), the main gases formed by the combustion of the char in air atmosphere include $\mathrm{CO}_{2}, \mathrm{CO}, \mathrm{NO}, \mathrm{NO}_{2}$, $\mathrm{N}_{2} \mathrm{O}$, HNCO and HCN. Among them, $\mathrm{CO}_{2}$ is the major gaseous product. This result is in good agreement with the study by Ashman et al.[8]. The infrared characteristic absorption peaks of $\mathrm{CO}_{2}$ and $\mathrm{CO}$ appear in $2358 \mathrm{~cm}^{-1}$ and $2181 \mathrm{~cm}^{-1}$, respectively [14]. The absorption peaks of NO, $\mathrm{NO}_{2}$ and $\mathrm{N}_{2} \mathrm{O}$ appear in $1808 \mathrm{~cm}^{-1}, 1631 \mathrm{~cm}^{-1}$ and $2243 \mathrm{~cm}^{-}$ 1 , respectively [15]. While the absorption peaks of $\mathrm{HCN}$ [16]、 $\mathrm{HNCO}$ and $\mathrm{NH}_{3}$ [17] appear in $713 \mathrm{~cm}^{-1}, 2250 \mathrm{~cm}^{-1}$ and $966 \mathrm{~cm}^{-1}$.

In the process of char burning, the nitrogenous substances are released by devolatilization and then $\mathrm{NO}_{x}$ is produced after the effect of char-nitrogen conversion. NO is the main kind of $\mathrm{NO}_{x}$. However, Figure 5 indicates that the yield of $\mathrm{NO}$ and $\mathrm{NO}_{2}$ are relatively small during the combustion of the char in air atmosphere with increasing of temperature. It is consistent with what another literature reported. The formation of NO was restricted through the high concentration oxygen in a certain temperature in the literature [18].

There are mainly two views about the formation mechanism of $\mathrm{N}_{2} \mathrm{O}$ in the char combustion. One view believes that $\mathrm{N}_{2} \mathrm{O}$ is produced in an isopic reaction. For example, the char-nitrogen transformed into HCN at first and then further transformed into $\mathrm{N}_{2} \mathrm{O}$. Some studies also indicated NO reacted with $\mathrm{H}_{2} \mathrm{O}$ to produce $\mathrm{N}_{2} \mathrm{O}$ and $\mathrm{OH}-$ at $673 \mathrm{~K}$ [15]. The other view believes heterogeneous reaction is the main reaction to generate $\mathrm{N}_{2} \mathrm{O}$ and the reactions on the surface of char are as follows [19]: curve

$$
\begin{aligned}
& \mathrm{C}(\mathrm{)}+\mathrm{NO} \rightarrow \mathrm{C}(\mathrm{N})+\mathrm{C}(\mathrm{O}) \\
& \mathrm{C}(\mathrm{N})+\mathrm{NO} \rightarrow \mathrm{N}_{2} \mathrm{O}+\mathrm{C}(\mathrm{)} \\
& \mathrm{C}(\mathrm{)})+\mathrm{N}_{2} \mathrm{O} \rightarrow \mathrm{C}(\mathrm{O})+\mathrm{N}_{2}
\end{aligned}
$$

Respectively, $\mathrm{C}(\mathrm{)}, \mathrm{C}(\mathrm{N})$ and $\mathrm{C}(\mathrm{O})$ represent carbon activity sites, surface carbon-nitrogen components and surface carbon-oxygen components. De Soete and others [20] demonstrated (-CN) on the surface of the char would transform into (-CNO) in aerobic environment and further transform into $\mathrm{NO}$ and $\mathrm{N}_{2} \mathrm{O}$.

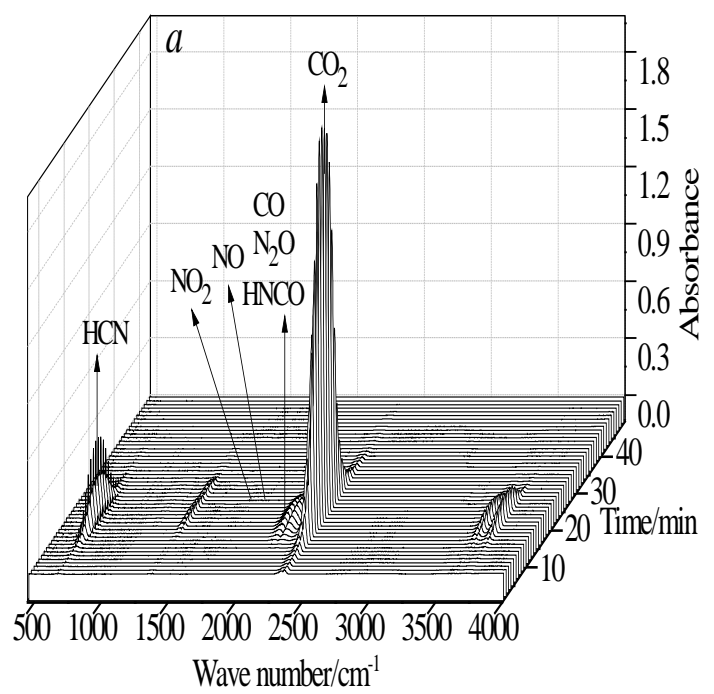

Figure 4. FTIR spectrogram of the char combustion in air atmosphere.

The Figure 5 shows that the formation trends of HCN, $\mathrm{HNCO}$ and $\mathrm{N}_{2} \mathrm{O}$ are basically the same, which are consistent with the rules reported in other literature [9]. The study of char-nitrogen fast pyrolysis mechanism was conducted by Nelson et al.[21] with FTIR and they found that HNCO was an important nitrogen-containing product which would be decomposed into free radical (-NCO) under some conditions soon. HCN was released into air atmosphere during the char combustion by FTIR. It was probably because the chemical connections of hydrogen in carbon rings were broken by oxygen and then reacted with nitrogen-containing groups to produce HCN [9]. The study conducted by Ashman et al.[8] proved that the main formation way of HCN was heterogeneous oxidation of char-nitrogen rather than its secondary devolatilization.

In this experiment, $\mathrm{NH}_{3}$ is not detected in the char combustion in air atmosphere. Other literatures [9, 22] also reported the similar phenomena. Winter et al.[22] studied gaseous nitrogen-product produced from the combustion and devolatilization of the char with FTIR and found that $\mathrm{NO}, \mathrm{N}_{2} \mathrm{O}$ and $\mathrm{HCN}$ were detected in the experiment while $\mathrm{NH}_{3}$ was not. It was probably because of the adsorption of $\mathrm{NH}_{3}$ in sample line of FTIR, low density of $\mathrm{NH}_{3}$ or time delay. $\mathrm{NH}_{3}$ was released through the hydrogenation reaction between $\mathrm{H}_{2}$ and nitrogenous aromatic compounds of coal or char [23]. According to this phenomenon, it can be inferred that little $\mathrm{NH}_{3}$ is released from superficial charnitrogen when char combustion in hydrogen-poor atmosphere, which is a possible cause of undetected $\mathrm{NH}_{3}$. 

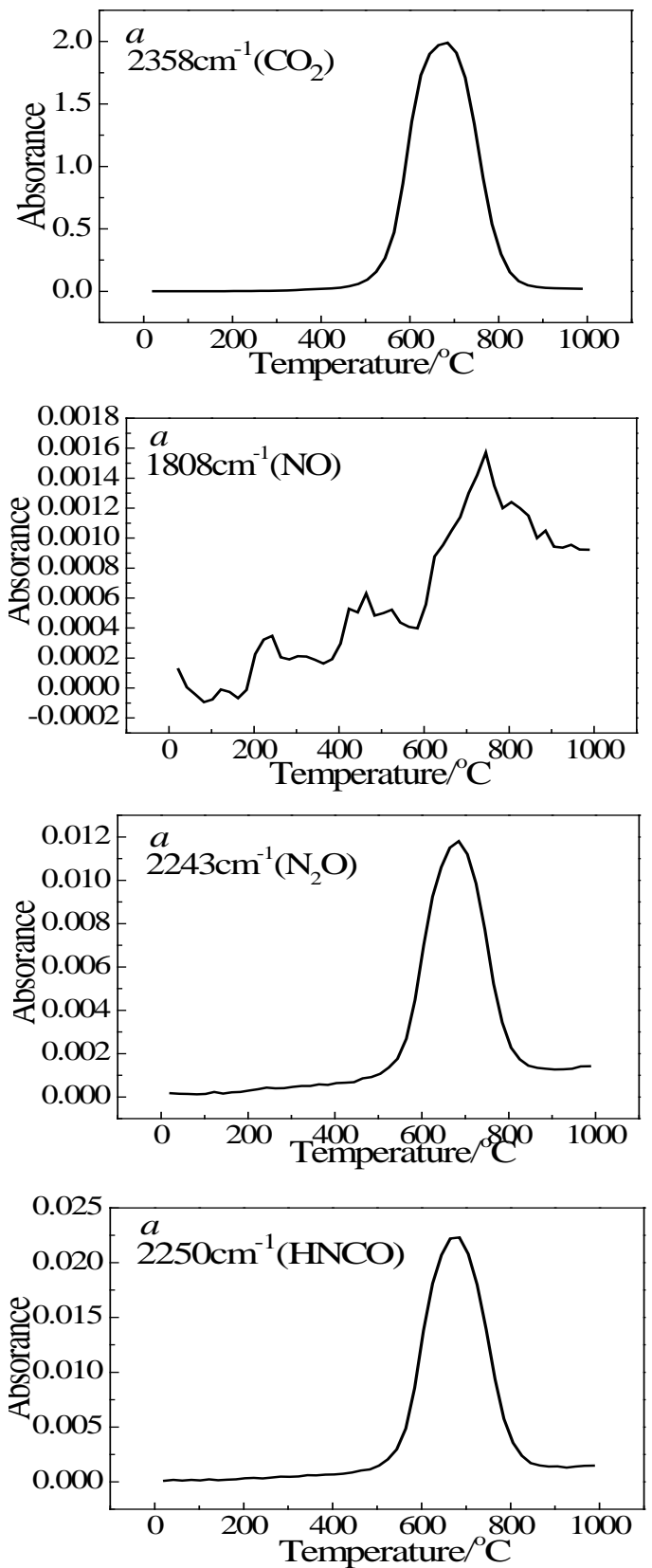
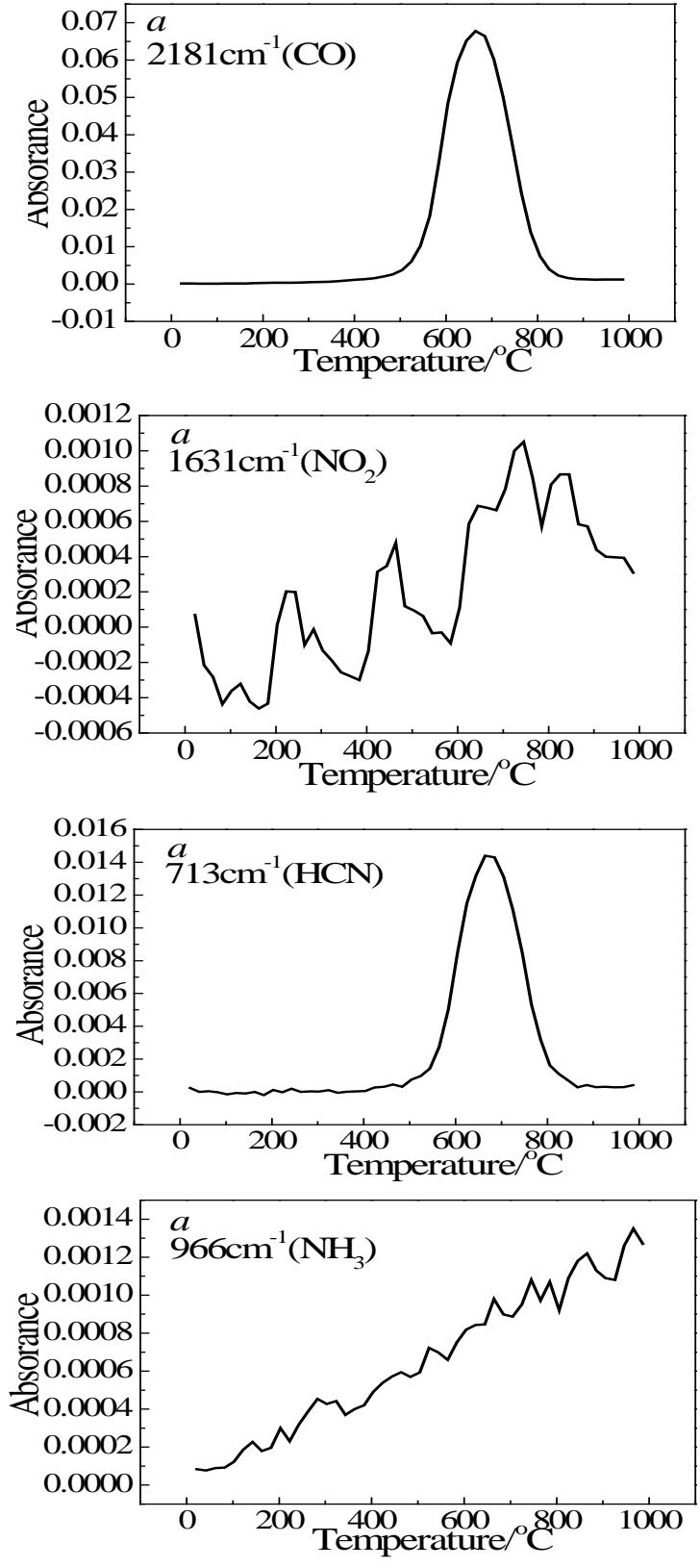

Figure 5. Relational graph between absorbance and temperature of the main gases released from the char at the infrared characteristic peaks.

\subsection{Correlation Analysis of TG and FTIR Data}

As DTG curve of Figure 3 shows, the combustion process of the experimental char is divided into three phases. As Figure 5 shows, only a little gaseous product is formed in the first phrase (From initial temperature to $460{ }^{\circ} \mathrm{C}$ ). In the second phase (From 460 to $756{ }^{\circ} \mathrm{C}$ ), all kinds of gaseous products $\left(\mathrm{CO}_{2}, \mathrm{CO}, \mathrm{NO}, \mathrm{NO}, \mathrm{N}_{2} \mathrm{O}\right.$, HNCO and HCN) are released more intensively and the absorbance of all the products peak in the temperature range (especially around $700{ }^{\circ} \mathrm{C}$ ). In the third phase (above $\left.756{ }^{\circ} \mathrm{C}\right)$, multiple gaseous products $\left(\mathrm{CO}_{2}, \mathrm{CO}, \mathrm{NO}, \mathrm{NO}\right.$, $\mathrm{N}_{2} \mathrm{O}$, HNCO and HCN) are continued to be formed but their yield reduces gradually. The TG-DTG curve is consistent with the results of FTIR according to the above contrast.

\section{Conclusions}

(1) The pyrrolic nitrogen ( $\mathrm{N}-5)$ in char is relative instability after high-temperature pyrolysis by comparing main occurrence modes of nitrogen between the experimental blended coal and the corresponding char. N-5 is released out of the char in the form of volatile gas during the process of pyrolysis. Otherwise $\mathrm{N}-5$ is transformed into pyridine nitrogen $(\mathrm{N}-6)$ or quaternary nitrogen $(\mathrm{N}-\mathrm{Q})$.

(2) The analysis of TG and kinetics of the char burning in air atmosphere indicates the TG curve of experimental char gradually falls in the range of $460 \sim 756{ }^{\circ} \mathrm{C}$ and the DTG curve reaches the peak at $666{ }^{\circ} \mathrm{C}$. A large amount of gases are produced in the process of the char combustion in air atmosphere. The activation energy of the char combustion is $93.9 \mathrm{KJ} / \mathrm{mol}$ in the range of the same temperature above based on the method of Coats-Redfern.

(3) The results of FTIR indicate that the main gases produced in the combustion of the char in air atmosphere include $\mathrm{CO}_{2}, \mathrm{CO}, \mathrm{NO}, \mathrm{NO}_{2}, \mathrm{~N}_{2} \mathrm{O}, \mathrm{HNCO}$ and $\mathrm{HCN}$. The yield of $\mathrm{CO}_{2}$ is the most, while the productions of $\mathrm{NO}$ and $\mathrm{NO}_{2}$ are the least. The formation trend of $\mathrm{HCN}, \mathrm{HNCO}$ and $\mathrm{N}_{2} \mathrm{O}$ is basically the same and $\mathrm{NH}_{3}$ is not detected in this experiment. 


\section{Acknowledgements:}

Research Funds for the Central Universities in China. The authors gratefully acknowledge the experiment support of Energy and Environmental Science Engineering Research Institute in North China Electric Power University.

\section{References}

[1] Y. Yu, M. H. Xu, D. X. Yu, Swelling characteristic of char particles and its influence on PM formation during combustion, Proc. Chin. Soc. Electr. Eng., 25, 112-116, 2005.

[2] C. J. Ping, J. H. Zhou, J. Cheng, Micro-physical and chemical properties and combustion reactivity of blended coal chars, J. Power Eng., 29, 174-177, 2009.

[3] J. H. Zhou, C. J. Ping, W. J. Yang, Thermo-gravimetric research on dynamic combustion reaction parameters of blended coals, J. Power Eng., 25, 207-210, 2005.

[4] H. Zhou, Y. Huang, G. Mo, Conversion of fuel-N to $\mathrm{N}_{2} \mathrm{O}$ and $\mathrm{NO}_{x}$ during coal combustion in combustors of different scale, Chin. J. Chem. Eng., 21, 999-1006, 2013.

[5] M. Li, J.H. Yang, Q.F. Zhang, XPS study on transformation of $\mathrm{N}$ - and S- functional groups during pyrolysis of high sulfur New Zealand coal, J. Fuel Chem. Technol., 41, 1287-1293, 2013.

[6] H. Cheng, Q. Liu, M. Huang, Application of TG-FTIR to study $\mathrm{SO}_{2}$ evolved during the thermal decomposition of coal-derived pyrite, Thermochim. Acta, 555, 1-6, 2013.

[7] Y. Y. Peng, S. B. Wu, Pyrolysis characteristics of bagasse alkali lignin, Chem. Ind. Eng. Prog., 31, 462467, 2012.

[8] P. J. Ashman, B. S. Haynes, A. N. Buckley, The fate of char-nitrogen in low-temperature oxidation, Symp. Combust., 27, 3069-3075, 1998.

[9] J. Chen, J. Zhang, Y. C. Zhang, Experimental study on char-nitrogen conversion in $\mathrm{O}_{2} / \mathrm{CO}_{2}$ atmosphere, $J$. Eng. Thermophys., 32, 145-148, 2011.

[10]Y. H. Liu, D. F. Che, Y. T. Li, X-ray photoelectron spectroscopy determination of the forms of nitrogen in Tongchuan coal and its chars, J. Xi'an Jiaotong Univ., 35, 661-665, 2001.

[11]J. R. Pels, F. Kapteijn, J. A. Moulijn, Evolution of nitrogen functionalities in carbonaceous materials during pyrolysis, Carbon, 33, 1641-1653, 1995.
The work was supported by National Natural Science Foundation of China (51206047) and the Fundamental

[12]M. A. Wójtowicz, J. R. Pels, J. A. Moulijn, The fate of nitrogen functionalities in coal during pyrolysis and combustion, Fuel, 74, 507-516, 1995.

[13]B. S. Ji, C. J. Yu, P. Wu, TG-FTIR analysis on pyrolysis characteristics of refuse-derived fuel, J. Chem. Ind. Eng., 64, 1042-1048, 2013.

[14]J. Y. Shi, Y. W. Liu, Z. Y. Wang, C. X. Wang, Investigation of thermal decomposition of ascorbic acid by TG-FTIR and thermal kinetics analysis, J. Pharm. Biomed. Anal., 77, 116-119, 2013.

[15]A. Wojtaszek, I. Sobczak, M. Ziolek, NO adsorption combined with FTIR spectroscopy as a useful tool for characterization of niobium species in crystalline and amorphous molecular sieves, Catal. Today, 192, 149153, 2012.

[16]NIST Chemistry Webbook Standard Reference Database, 69, 2005, release, http://webbook.nist.gov/ chemistry.

[17]A. M. Mocanu, C. Moldoveanu, L. Odochian, Study on the thermal behavior of casein under nitrogen and air atmosphere by means of the TG-FTIR technique, Thermochim. Acta, 546, 120-126, 2012.

[18]Y. Lu, A. Jahkola, "Fuel nitrogen behavior during devolatilization and char oxidation under fluidized bed combustion conditions": Proceedings of the third international symposium on coal combustion, Science and Technology, Turku, Finland, 1995, pp. 457-466.

[19]X. X. Zhang, Z. J. Zhou, J. H. Zhou, A density functional study of heterogeneous formation and decomposition of $\mathrm{N}_{2} \mathrm{O}$ on the surface of char, J. Fuel Chem. Technol., 39, 806-81, 2011.

[20]G. G. De Soete, E. Croiset, J. R. Richard, Heterogeneous formation of nitrous oxide from char-bound nitrogen, Combust. Flame, 117, 140-154, 1999.

[21]P. F. Nelson, C. Li, E. Ledesma, Formation of HNCO from the rapid pyrolysis of coals, Energy Fuels, 10, 264-265, 1996.

[22]F. Winter, C. Wartha, G. Löffler, The $\mathrm{NO}$ and $\mathrm{N}_{2} \mathrm{O}$ formation mechanism during devolatilization and char combustion under fluidized-bed conditions, Int. Symp. on Combust., 26, 3325-3334, 1996.

[23]L. J. Mckenzie, F. Tian, C. $\mathrm{Li}, \mathrm{NH}_{3}$ formation and destruction during the gasification of coal in oxygen and steam, Environ. Sci. Technol., 41, 5505-5509, 2007. 